\title{
O ser e o nada em Álvaro de Campos
}

MARIA ESTHER MACIEL

\section{ANTI-SONETO DA NAO-MATERIA}

Na não-matéria agora estou, e existo O pensamento pensa o pensamento.

A ostra pensa a pérola por dentro Sou meu reverso espelho e me contristo.

Na não-matéria, muitas vezes, tento Em ser matéria pura, ou ser um misto Na não-matéria não consigo isto, $E$ já que não consigo, falo, invento.

E finjo ser figura e sombra e luz E finjo pro meu povo que sou pus, que sou um resto puro de alvorada.

Na não-matéria não se logra, é triste! $E$ a gente fica sendo, porque existe, Vaga ilusăo de ser, não sendo nada.

\section{ALTINO CAIXETA DE CASTRO}

Alvaro de Campos é o poeta do sentir: sente tudo o que, no fundo, é reduzido a um mistério do nada. Sente o real que foge 
por entre sua frágil percepçăo de ser-al-para-a-morte. Sente a totalidade destotalizante de seu próprio eu em confluência com os outros. Sente, porque sentir é a metafísica da poesia. Metafísica, na acepção de Fernando Pessoa, como atividade artietica e nåo científica. ${ }^{1}$

O ser de Alvaro de Campos é um ser-para-si à cata de seu em-si diluido no tudo, que, na verdade, é o próprio nada:

«Tenho que arrumar a mala de sen» 2

Mas o que é o ser, senão uma dualidade com o não-ser?

Parmênides foi o primeiro a sentir essa dualidade. 0 ser, para ele, já era um conceito tão evidente, que se definia pela sua própria negação, se esclarecia na conceituaçăo do não-ser. Com isso, admitia 0 incorpório, o nada circundante.

Aristóteles, mais tarde, declarou, entretanto, que «mesmo do nåo-ser, dizemos que ele é não-sen», anulando, assim, o conceito do nada do pensamento racional, como o fizeram os pragmatistas ao recusarem o que para eles nåo queria dizer nada: o nada. Até que a ontologia surgisse para resgatá-lo e transformá-lo numa nova filosofia.

o que é o nada? A pergunta é um paradoxo, pois se formula na sua própria negação. Mas se o nada não é, ele existe, como pressu. posto da existência do ser. Negar năo implica a năo-existência de algo:

«A condição necessária para que seja possivel dizer-se 'não', é que exista o nẫo-ser (o nada) em nós e fora de nós, e que o nada persista e esteja sempre presente no ser, co-habite o sens. (Sartre) ${ }^{3}$

O ser e o nada compõem a realidade humana.

«Ah, perante esta única realidade, que é o mistério,

Perante esta única realidade terrivel - a de haver uma realidade

Perante este horrivel ser que é haver ser,

Perante este abismo de existir um abismo,

Ser um abismo por simplesmente ser,

Por poder ser,

Por haver ser! 
O homem como um problema para si mesmo. O homem diante do seu próprio nada. $O$ que $e$ isso senão a angústia? $O$ nada se revela nessa sensação de abismo que ameaça o ser-no-mundo. Quando o existir não é mais do que o «ex-sistin», ou o estar suspenso num vazio.

«Nāo sou nada.

Nunca serei nada.

Não posso querer ser nada.

A parte isso, tenho em mim todos os sonhos do mundo».

\section{(A. C.) 6}

A angústia, como queda no inautêntico (Heidegger), ou como uma necessidade de escolha (Sartre). 0 confronto com 0 nada, pois nåo só toda escolha é uma escolha de finitude, como toda queda é um sentir-se mortal. A angústia sartreana é um desejo de ser em-si, que, por ser intemporal e imutável, é nadificado pelo para-si. (Enten. dendo-se o em-si como um fenómeno, e o para-si como consciência). A angústia de Heidegger é a do estar-ai do homem naufragado em suas possibilidades.

«Súbita, uma angústia,

Ah, angústia, que náusea do estômago à alma».

(A. C.) 6

«Esta velha angústia,

Esta angústia que trago há séculos em mim, transbordou da vasilhas.

(A. C.) 7

A angústia do poeta é a angústia inerente do ser. Heidegger diz que o homem é um ser-no-mundo, sendo, essencialmente, um poder-ser, um ser de ultrapassagem e de projeto. Mas, lançado al, sujeito às intempéries do mundo, despessoalizado na facticidade de um todo que o obriga a ser o que não deseja, ou a sentir-se «tão real quanto uma metáfora».8 Assim é Alvaro de Campos, que traz dentro 
do coração, como um cofre que se nāo pode fechar de cheio, todos os lugares, todos os portos, todas as paisagens, mas para quem, tudo isso, .. que é tanto, torna-se pouco diante do que quer.9

«Vivi todas as emoçōes, todos os pensamentos, todos os gestos, E fiquei triste como se tivesse querido vivê-los e não conseguisse».

(A. C.) 10

o ser-aí retrai o seu possivel e queda-se no inautêntico, no impessoal, consciente da sua precariedade original. Seu eu se nadifica no tudo: a consciência infeliz de quem viveu tudo, mas com a sensaçăo da nulidade de seu próprio eu.

Álvaro de Campos é esse assombro do homem diante do mundo. E esse sentir-se, ao mesmo tempo, em excessos e ausências, nunca sendo bastante. E o DASEIN de Heidegger, o ser jogado à revelia de si mesmo.

«Seja o que for, era melhor não ter nascido».

\section{(A. C.) 11}

O homem carrega, desde o nascimento, a marca de sua orfandade original. Lançado do nada para o nada, recria-se em sua possibilidade de ser. E nessa busca da transcendência do que é, descobre sua finitude. $E$ cai no indizivel:

«Que há de ser de mim? Que há de ser de mim3»

$$
\text { (A. C.) } 12
$$

«Mary, eu sou infeliz...

Freddie, eu sou infeliz...»

(A. C.) 18

O homem, enquanto ser-no-mundo, é, essencialmente, preocupação. Preocupação com o seu vir-a-ser que é a morte. Heidegger fundamenta 
essa preocupação na temporalidade, ou seja, no estado de ser temporal do homem. O homem, perdido no inautêntico, no seu Dasein, não é apenas um «ser-ai-simplesmente-assim», mas um «ser-ai-simplesmentepara-nada». A angústia diante da morte faz parte de sua própria vida.

«O homem é uma sintese de inf nito e de finito, de temporal e de eterno, de liberdade e necessidade, é, em suma, uma sintese».

(Kierkegaard) 14

Álvaro de Campos é o poeta dessa sintese de tudo e nada. E por isso mesmo não existe enquanto um eu, sujeito de sua liberdade. Está lançado na contingência de si mesmo:

«Não: não quero nada.

Já disse que não quero nada.

Não me venham com conclusões!

A única conclusão é morren».

(A. C.) 15

A morte apresenta-se como o fim de seu projeto de ser. Porque está inserida no próprio ser. Como diz Otávio Paz, «o ser é a condição prévia do nada, porque a morte nasce da vida, podemos nomeá-la e assim reintegrá-las. Podemos nos aproximar do nada pelo ser. $E$ do ser, pelo nada. Somos o fundamento de uma negatividade, mas também a transcendência dessa negatividade». ${ }^{16}$

Quando o homem se depara com a morte, aflora-se a carência de ser, que pode ser revestida de desespero (Kierkegaard) ou do que Sartre chama de tédio fundamental ou náusea. Tudo se reduz a uma «lassidão gelatinosa», uma «ignóbil pasta», um terrivel nada. A vida passa a ser apenas um motivo para a morte, apesar dos outros vários motivos que nossa liberdade não escolheu.

«Queria vomitar o que vi, só da náusea de o ter visto, Estômago da alma alvorotado de eu ser...» 
«Onde supus o meu ser,

Fogem desmantelados, últimos restos

da ilusão final,

Os meus exércitos sonhados, derrotados sem ter sido,

as minhas coortes por existir, esfaceladas em Deus».

(A. C.) 18

«Não durmo, jazo, cadáver acordado, sentindo»

$$
\text { (A. C.) } 10
$$

A morte, segundo Heidegger, vive em constante maturação no homem, sendo um a priori da nossa condição. Alvaro de Campos vive essa morte, e vivê-la por um instante é vivê-la eternamente. Daí surge a intemporalidade que permeia a nossa finitude. A síntese fundamental de que é formada a realidade humana e de onde brota a própria poesia.

\section{NOTAS}

1. Alvaro de Campos nas Idélas filosofficas, nega a concepç̧o de metafisica de Fernando Pessoa, alegando que este confunde o que $\mathrm{e}$ arte com o que a ciência năo é.

2. CAMPOS, Alvaro de. Grandes são os desertos. In:- Obra Pótica. Såo Paulo, Agullar, 1981, p. 316.

3. OLSON, Robert G. Introduçăo ao existencialismo, Såo Paulo, Brasiliense, 1970.

4. CAMPOS, Alvaro de. Ah, perante esta única realidade. In: op. cit. p. 336.

5. Tabacaria. In: op. cit. p. 296.

6. Bicabornato de Soda. In.: op. cit. p. 314.

7. —u Esta velha angústla... In: op. cit. p. 324.

8. - Passagem das Horas. In: op. cit. p. 275.

9. Op. cit. p. 276.

$10 . \longrightarrow$ Op. cit. p. 277.

11. Op. cit. p. 276. 
12. Op. cit. p. 279.

13. - Op. cit. p. 279.

14. KIERKEgaARD, Sören. O desespero humano. Porto, Tavares Martins, 1979, p. 33.

15. CAMPOS, Alvaro de. Lisbon Revisited (1923). In: op. cit. p. 290.

16. PAZ, Otávio. O arco a lira. Rio de Janeiro, Nova Fronteira, 1982, p. 183.

17. CAMpos, Alvaro de. Ah, onde estou ou onde passo... In: op. cit. p. 345.

18. Lisbon Revisited (1926). In: op. cit. p. 223.

19. Insônia. In: op. cit. p. 308.

\section{BIBLIOGRAFIA}

ARRUDA, Elson. A angústia e o nada. Kriterion, Belo Horizonte, UFMG, (71), 1978. BEAUFRET, Jean. Introdugho d̀s filosofias da existancla. Såo Paulo, Duas Cidades, 1976.

HEJDEGGER, Martin. Introdugso a metafisica, Rio de Janeiro, Tempo Brasileiro, 1978.

Sobre o problema do ser. S\&o Paulo, Duas Cidades, 1969.

Tempo e ser. Så Paulo, Abril Cultural, 1979. (Col. Os Pensadores).

KIERKEGAARD, Sören. O desespero humano. Porto, Tavares Martins, 1979.

MACDOWELL, J. A. A genese da ontologia fundamental de Martins Heidegger.

Sao Paulo, USP, 1970.

OLSON, Robert G. Introduçåo ao existenclallsmo. Săo Paulo, Brasiliense, 1970. PAZ, Octávio. O arco e a lira. Rio de Janeiro, Nova Frontfira, 1982.

PESSOA, Fernando. Obra postlea. Rio de Janeiro, Nova Aguilar, 1981.

Obras em prosa, Rio de Janeiro, Nova Aguilar, 1982.

SARTRE, Jean Paul. O existencialtsmo 6 um humanismo. Såo Paulo, Abril Cultural, 1979. (Col. Os Pensadores). 